\title{
Design of Peltier Element Based on Semiconductors with Hopping Electron Transfer via Defects
}

\author{
N.A. Poklonski, S.A. Vyrko, A.I. Kovalev, I.I. Anikeev, N.I. Gorbachuk \\ Belarusian State University, \\ Nezavisimosti Ave., 4, Minsk 220030, Belarus
}

Received 28.01.2021

Accepted for publication 09.03.2021

The study of thermoelectric properties of crystalline semiconductors with structural defects is of practical interest in the development of radiation-resistant Peltier elements. In this case, the spectrum of energy levels of hydrogen-like impurities and intrinsic point defects in the band gap (energy gap) of crystal plays an important role.

The purpose of this work is to analyze the features of the single-electron band model of semiconductors with hopping electron migration both via atoms of hydrogen-like impurities and via their own point triplecharged intrinsic defects in the $c$-and $v$-bands, as well as to search for the possibility of their use in the Peltier element in the temperature range, when the transitions of electrons and holes from impurity atoms and/or intrinsic defects to the $c$ - and $v$-bands can be neglected.

For Peltier elements with electron hopping migration we propose: (i) an $h$-diode containing $\mid \mathrm{d} 1$ )- and d2)-regions with hydrogen-like donors of two types in the charge states $(0)$ and $(+1)$ and compensating them hydrogen-like acceptors in the charge state $(-1)$; (ii) a homogeneous semiconductor containing intrinsic $t$-defects in the charge states $(-1,0,+1)$, as well as ions of donors and acceptors to control the distribution of $t$-defects over the charge states. The band diagrams of the proposed Peltier elements in equilibrium and upon excitation of a stationary hopping electric current are analyzed.

A model of the $h$-diode containing hydrogen-like donors of two types $\mid \mathrm{d} 1)$ and $\mid \mathrm{d} 2$ ) with hopping migration of electrons between them for $50 \%$ compensation by acceptors is considered. It is shown that in the case of the reverse (forward) electrical bias of the diode, the cooling (heating) of the region of the electric double layer between $\mid \mathrm{d} 1)$ - and $\mid \mathrm{d} 2)$-regions is possible.

A Peltier element based on a semiconductor with point $t$-defects is considered. It is assumed that the temperature and the concentration of ions of hydrogen-like acceptors and donors are to assure all $t$-defects to be in the charge state (0). It is shown that in such an element it is possible to cool down the metal-semiconductor contact under a negative electric potential and to heat up the opposite contact under a positive potential.

Keywords: doped semiconductor, diode with hydrogen-like donors of two types, triple-charged intrinsic point defects, electron hopping migration, Peltier element.

DOI: $10.21122 / 2220-9506-2021-12-1-13-22$

\begin{tabular}{ll}
\hline Адрес для переписки: & Address for correspondence: \\
Поклонский Н.А. & Poklonski N.A. \\
Белорусский государственный университет, & Belarusian State University, \\
пр-т Независимости, 4, г. Минск 220030, Беларусь & Nezavisimosti Ave., 4, Minsk 220030, Belarus \\
e-mail: poklonski@bsu.by; poklonski@tut.by & e-mail: poklonski@bsu.by; poklonski@tut.by \\
\hline Для цитирования: & For citation: \\
N.A. Poklonski, S.A. Vyrko, A.I. Kovalev, I.I. Anikeev, N.I. Gorbachuk. & N.A. Poklonski, S.A. Vyrko, A.I. Kovalev, I.I. Anikeev, N.I. Gorbachuk. \\
Design of Peltier Element Based on Semiconductors with Hopping & Design of Peltier Element Based on Semiconductors with Hopping \\
Electron Transfer via Defects. & Electron Transfer via Defects. \\
Приборы и методы измерений. & Devices and Methods of Measurements. \\
2021.- Т. 12, № 1.-С. 13-22. & 2021, vol. 12, no. 1, pp. 13-22. \\
DОI: $10.21122 / 2220-9506-2021-12-1-13-22$ & DOI: 10.21122/2220-9506-2021-12-1-13-22 \\
\hline
\end{tabular}




\title{
Схема элемента Пельтье на полупроводниках с прыжковым переносом электронов по дефектам
}

\author{
Н.А. Поклонский, С.А. Вырко, А.И. Ковалев, И.И. Аникеев, Н.И. Горбачук \\ Белорусский государственный университет, \\ пр-т Независимости, 4, г. Минск 220030, Беларусь
}

Поступила 28.01.2021

Принята к печати 09.03.2021

Исследование термоэлектрических свойств кристаллических полупроводников с дефектами структуры представляет практический интерес при создании радиационно-стойких элементов Пельтье. При этом важную роль играет спектр уровней энергии водородоподобных примесей и собственных точечных дефектов в энергетической щели (запрещённой зоне) кристалла.

Цель работы - анализ особенностей одноэлектронной зонной модели полупроводников с прыжковой миграцией электронов как по атомам водородоподобных примесей, так и по собственным точечным трёхзарядным дефектам, а также поиск возможности их использования в элементе Пельтье в области температур, когда переходами электронов и дырок с атомов примесей и/или собственных дефектов в $c$ - и $v$-зоны можно пренебречь.

В качестве элементов Пельтье с прыжковой миграцией электронов предложены: 1) $h$-диод, содержащий $\mid \mathrm{d} 1)$ - и $\mid \mathrm{d} 2)$-области с водородоподобными донорами двух сортов в зарядовых состояниях $(0)$ и (+1) и компенсирующие их водородоподобные акцепторы в зарядовом состоянии $(-1) ; 2)$ однородный полупроводник, содержащий собственные $t$-дефекты в зарядовых состояниях $(-1,0,+1)$, а также ионы доноров и акцепторов для управления распределением $t$-дефектов по зарядовых состояниям. Проанализированы зонные диаграммы предлагаемых элементов Пельтье в равновесии и при возбуждении стационарного прыжкового электрического тока.

Рассмотрена модель $h$-диода, содержащего водородоподобные доноры двух сортов $\mid \mathrm{d} 1)$ и $\mid \mathrm{d} 2$ ) с прыжковой миграцией между ними электронов при компенсации их на $50 \%$ акцепторами. Показано, что при обратном (прямом) электрическом смещении диода возможно охлаждение (нагревание) области двойного электрического слоя между $\mid \mathrm{d} 1)$ - и $\mid \mathrm{d} 2)$-областями.

Рассмотрен элемент Пельтье на основе полупроводника с точечными $t$-дефектами. Принималось, что температура, а также концентрации ионов водородоподобных акцепторов и доноров таковы, что практически все $t$-дефекты находятся в зарядовом состоянии (0). Показано, что в таком элементе возможно охлаждение контакта металл-полупроводник, находящегося под отрицательным электрическим потенциалом, и нагревание противоположного контакта, под положительным потенциалом.

Ключевые слова: легированный полупроводник, диод с водородоподобными донорами двух сортов, трёхзарядные собственные точечные дефекты, прыжковая миграция электронов, элемент Пельтье.

DOI: $10.21122 / 2220-9506-2021-12-1-13-22$

\begin{tabular}{ll}
\hline Адрес для переписки: & Address for correspondence: \\
Поклонский Н.А. & Poklonski N.A. \\
Белорусский государственный университет, & Belarusian State University, \\
пр-т Независимости, 4, г. Минск 220030, Беларусь & Nezavisimosti Ave., 4, Minsk 220030, Belarus \\
e-mail: poklonski@bsu.by; poklonski@tut.by & e-mail: poklonski@bsu.by; poklonski@tut.by \\
\hline Для цитирования: & For citation: \\
N.A. Poklonski, S.A. Vyrko, A.I. Kovalev, I.I. Anikeev, N.I. Gorbachuk. & N.A. Poklonski, S.A. Vyrko, A.I. Kovalev, I.I. Anikeev, N.I. Gorbachuk. \\
Design of Peltier Element Based on Semiconductors with Hopping & Design of Peltier Element Based on Semiconductors with Hopping \\
Electron Transfer via Defects. & Electron Transfer via Defects. \\
Приборы и методы измерений. & Devices and Methods of Measurements. \\
2021.- Т. 12, № 1.-С. 13-22. & 2021, vol. 12, no. 1, pp. 13-22. \\
DОI: $10.21122 / 2220-9506-2021-12-1-13-22$ & DOI: 10.21122/2220-9506-2021-12-1-13-22 \\
\hline
\end{tabular}




\section{Introduction}

Thermoelectric phenomena in semiconductor systems caused by the migration of electrons in the $c$-band and holes in the $v$-band are intensively studied (see, e. g., [1-7]). The thermopower was measured for hopping migration of holes via hydrogenlike acceptors of the same type in homogeneous germanium crystals at liquid helium temperatures and below $[8,9]$; see also [10].

The efficiency of semiconductor materials used in thermoelectric converters is determined by the dimensionless thermoelectric figure of merit $Z T$ and by the Peltier coefficient $\Pi$ (see, e. g., [11-13]):

$$
Z T=\frac{\sigma S^{2} T}{\kappa} ; \quad \Pi=S T,
$$

where $Z$ is the figure of merit $\left[\mathrm{K}^{-1}\right], T=\left(T_{1}+T_{2}\right) / 2$ is the operating temperature $[\mathrm{K}], T_{1}$ and $T_{2}$ are the absolute temperatures of hot and cold electrodes to the material, $\sigma$ is the direct current specific electrical conductivity $\left[\mathrm{Ohm}^{-1} \cdot \mathrm{m}^{-1}\right], S$ is the Seebeck coefficient (or thermopower) $[\mathrm{V} / \mathrm{K}], \kappa$ is the thermal conductivity $\left[\mathrm{W} \cdot \mathrm{m}^{-1} \cdot \mathrm{K}^{-1}\right], \Pi$ is the Peltier coefficient $[\mathrm{V}]$.

Note that the Peltier coefficient $\Pi$, as a rule, is not measured directly, but is calculated from Eq. (1) by the value of the Seebeck coefficient $S$, which is easier to measure.

There are various ways to increase the thermoelectric figure of merit (see, e. g., [12-14], as well as the reviews on this topic [15-19]): selection of the optimal concentration of mobile charge carriers (electrons, holes or ions) in homogeneous materials; selection of the optimal band gap (energy gap); changing the chemical composition of materials (e. g., by chemical doping or neutron transmutation doping) or modifying their structure by introducing, for example, radiation defects. The possibilities of increasing of the thermoelectric figure of merit of nanostructured materials consisting of lowdimensional systems are also considered [1]. Realistic estimates of the limiting values of figure of merit of thermoelectric composites are given in [3].

Investigation of the optimal band gap $E_{\mathrm{g}}$ of a semiconductor showed that the condition $E_{\mathrm{g}} \gg k_{\mathrm{B}} T$ should be fulfilled [4]. This is easily explained by the fact that for the Fermi level lying near the bottom of the $c$-band, the concentration of minority carriers (holes in the $v$-band), and as a consequence, their contribution to the thermopower can be neglected. However, this method makes it possible to increase the $Z T$ value insignificantly. The modifica- tion of the chemical composition and disordering of the structure consists in the preparation of solid solutions or the growth of disordered alloys based on them; in the selection of the optimal concentrations of these compounds; combining them. Some samples obtained by such methods demonstrated thermoelectric figure of merit up to $Z T=2.2$ at room temperature (see, e. g., [14]).

The existence of an optimal doping level is due to the fact that an increase in the concentration of mobile charge carriers (electrons and/or holes) usually increases the electrical conductivity $\sigma$, but decreases the Seebeck coefficient $S$ (see Eq. (1)). Due to an increase in the concentration of charge carriers, they become degenerate and the Fermi level goes into the $c$-band (or in the $v$-band). In this case, the energy and velocities of electrons (or holes) will be determined by the Fermi level (Fermi energy) and will practically not depend on temperature. As a consequence, the charge fluxes from the hot and from the cold electrodes to the sample will hardly differ.

A Peltier element is a thermoelectric twoterminal device. When a stationary electric current is excited in it, it cools down at one contact (electrode) of the element and heats up at the other electrode. The Peltier element is still attractive for applications as a silent and environmentally friendly device. It can be used as a thermoelectric generator operating by utilizing heat losses in other devices and working substances.

Typically, Peltier elements consist of $n$ - and $p$ type semiconductors connected in series with metal bridges. The contacts, which are cooled when passing an electric current, are placed on one surface of the Peltier element, and the contacts, which are heated, on the opposite surface. In the $p$ - and $n$ branches of the electrical circuit of the Peltier element, holes and electrons move from the cooled surface to the heated one [20,21].

Heat release power (energy released per unit time at the contact of a unit area) of the Peltier element $\left[\mathrm{W} \cdot \mathrm{m}^{-2}\right]$ :

$$
W=\frac{Q}{A t}=\left(\Pi_{1}-\Pi_{2}\right) \frac{I t}{A t}=\left(\Pi_{1}-\Pi_{2}\right) J,
$$

where $Q$ is the heat released at the contact [J], $A$ is the cross-section area of the contact $\left[\mathrm{m}^{2}\right], t$ is the time [s], $\Pi_{1}$ and $\Pi_{2}$ are the Peltier coefficients of materials 1 and 2 brought into electric and thermal contact [V], $I$ is the electric current $[\mathrm{A}], J$ is the electric current density $\left[\mathrm{A} / \mathrm{m}^{2}\right]$; It is the charge passing through the electrical contact of two 
different conductors $[\mathrm{C}]$. The value $W>0$ if heat is released, and $W<0$ if heat is absorbed.

In the work [22] the $p-n$ junction is considered as a potential thermoelectric device. Note that for the effective functioning of the $p-n$ diode as a Peltier element, the width of the electric double layer in the $p-n$ diode must be comparable or less than the diffusion length of electrons in the $c$-band and the diffusion length of holes in the $v$-band. Electrons and holes formed in the electric double layer due to the absorption of heat in it go into electrical ohmic contacts (of $n^{+}$- and $p^{+}$-type) to the $n$ - and $p$-type regions under the action of both the internal potential difference and the external electrical bias. In this case, the time of the drift "flight" of electrons and holes through the double layer should be less than their recombination lifetime [23].

Most works on thermoelectricity proceed from the band theory of crystalline solids and consider the migration of electrons delocalized in the $c$-band and $v$-band holes.

Within the framework of the band theory of crystalline solids, first proposed by Wilson (see essay [24]) on the basis of quantum mechanics, materials were distinguished by their electrical properties into insulators, semiconductors, and metals according to their single-electron energy spectrum. Subsequently, this led to the creation of the first bipolar transistors (see, e. g., $[25,26]$ ) on germanium crystals, as well as integrated circuits on silicon [27]. Charge coupled devices (based on the metal-insulator-semiconductor structure) were invented [28, 29], which made it possible to record optical images in digital form. Finally, the features of the electron energy spectrum of layered semiconductor structures, called semiconductor heterostructures, consisting of semiconductor materials with different band gap, were used to create semiconductor lasers $[30,31]$ that operate at room temperature and above. Nevertheless, the potential of defects in the crystal structure of semiconductors for creating devices based on them is far from being realized within the limits of the possible.

It is known that the properties of semiconductors containing crystal structure defects substantially depend on the type of defects, their concentration, and spatial distribution (see, e. g., [32, 33]). In this regard, it is of practical interest to study the thermoelectric properties of semiconductor materials with hopping electron migration via impurity atoms and/or intrinsic point defects of the crystal matrix.

Let us briefly consider the possible arrangements of the energy levels of impurity atoms (hy- drogen-like donors of two types) or intrinsic point triple-charged defects of the crystal structure in the band gap of semiconductors, suitable for the development of Peltier elements on their basis.

In crystalline semiconductors doped with hydrogen-like impurities at low temperatures, $c$-band electrons are "frozen out" on donors ( $v$-band holes on acceptors). In this case, electrical conduction is carried out through the hopping migration of electrons (or holes) via impurity atoms. For example, it was shown in [34] that the hopping migration of holes via boron atoms (as acceptors) and electrons via phosphorus atoms (as donors) in diamond occurs even at room temperature (see also [35]). However, impurity atoms with an increase in their concentration in the crystal matrix form clusters (associates) [36]. In general, hopping electrical conduction in crystals at room temperature can be realized via $t$-defects - radiation point defects of one type in three charge states $(-1,0,+1)$. Such radiation defects make it possible to significantly modify the electrical properties of semiconductors without changing their chemical composition [37-39].

The purpose of the work is to analyze the manifestation of the arrangement of the energy levels of atoms of hydrogen-like impurities or intrinsic point defects in the band model of crystalline semiconductors with hopping electron migration for the design of the Peltier element.

In this paper, two possible schemes for the implementation of Peltier elements based on two semiconductor systems with hopping electron migration between ohmic contacts (electrodes) to these systems are considered.

The first system is a flat crystalline semiconductor sample, on the one side doped with hydrogen-like donors with thermal ionization energy $E_{\mathrm{d} 1}$, and on the other side - with hydrogen-like donors with ionization energy $E_{\mathrm{d} 2}<E_{\mathrm{d} 1}$. Donors of two types can be in charge states $(0)$ and $(+1)$. Each donor introduces one energy level into the band gap. The degree of compensation by hydrogen-like acceptors is approximately $50 \%$. The hopping transfer of electrons via donors is "refracted" at the region of the electric double layer between the $\mid \mathrm{d} 1)$ and |d2)-regions of the system, which form the $h$ diode. Thus, the $h$-diode contains a $\mid \mathrm{d} 1)-\mid \mathrm{d} 2)$ junction and ohmic contacts to $\mid \mathrm{d} 1)$ - and $\mid \mathrm{d} 2)$-regions. (The properties of ohmic contacts to such semiconductors are presented in reviews $[40,41]$.)

The second system is a partially disordered semiconductor containing radiation $t$-defects in the dominating concentration, each of which can be in one of three charge states $(-1,0,+1)$. Each $t$-defect 
introduces two energy levels into the band gap. Hydrogen-like donors and acceptors are ionized and control the number of $t$-defect charge states that are realized at a given temperature.

\section{Design 1 - hopping electron migration via donors of two types}

In contrast to works [8-10], let us consider an $n$-type crystalline semiconductor doped with hydrogen-like donors of two types $(\mid \mathrm{d} 1)$ and $\mid \mathrm{d} 2))$ with different thermal ionization energies $\left(E_{\mathrm{d} 1}>E_{\mathrm{d} 2}\right)$; see Figure $1 a$. The charge states $(0)$ and $(+1)$ of $\mid \mathrm{d} 1)$ donors in the region $x<x_{\mathrm{j}}=0$ and $\left.\mid \mathrm{d} 2\right)$ donors in the region $x>x_{\mathrm{j}}$ provide the possibility of hopping electrical conduction. Compensating acceptors of one type $\mid \mathrm{a})$, uniformly distributed along the $x$ axis, are in the charge state $(-1)$. Fluctuations in the energy levels of impurities are not shown. Short lines within the band gap indicate the mean values of the donor ionization energy.

We assume that all hydrogen-like donors $\mid \mathrm{d} 1$ ) and $\mid \mathrm{d} 2)$ with concentrations $N_{\mathrm{d} 1}(x)$ and $N_{\mathrm{d} 2}(x)$ are immobile and are in charge states $(0)$ and $(+1)$, and their distribution along the $x$ coordinate (along the diode) is determined as follows [42]:

$$
N_{\mathrm{d} 1}(x)=\frac{N_{\mathrm{d} 1}}{1+\exp (x / l)}, \quad N_{\mathrm{d} 2}(x)=\frac{N_{\mathrm{d} 2}}{1+\exp (-x / l)},
$$

where $N_{\mathrm{d} 1}$ and $N_{\mathrm{d} 1}$ are the maximum concentrations of $\mid \mathrm{d} 1)$ and $\mid \mathrm{d} 2$ ) donors $\left[\mathrm{m}^{-3}\right]$; $l$ is the doping profile parameter $[\mathrm{m}] ; x=x_{\mathrm{j}}=0$ in Figure 1 corresponds to $N_{\mathrm{d} 1}\left(x_{\mathrm{j}}\right)=N_{\mathrm{d} 1}$ and $N_{\mathrm{d} 2}\left(x_{\mathrm{j}}\right)=N_{\mathrm{d} 2}$. The concentration of hydrogen-like acceptors $N_{\mathrm{a}}$ does not depend on the $x$ coordinate; all acceptors are in the charge state $(-1)$.

To implement $h$-diode with the Peltier effect on $n$-type silicon crystal, in the capacity of $\mid \mathrm{d} 1)$ donors we can take arsenic atoms (As) with thermal ionization energy $I_{\mathrm{d} 1}=53.8 \mathrm{meV}$ and in the capacity of $\mathrm{d} 2$ ) donors - antimony atoms (Sb) with thermal ionization energy $I_{\mathrm{d} 2}=42.7 \mathrm{meV}$ [43]. Boron (B) or aluminium $(\mathrm{Al})$ atoms can be taken as compensating acceptors.

The critical donor concentration $N_{\mathrm{d}}=N_{\mathrm{M}}$, corresponding to the low-temperature transition of a semiconductor crystal from the insulator state to the metallic one (the Mott transition), is given by the relation [44]:

$$
N_{\mathrm{M}}^{1 / 3} a_{\mathrm{H}}=\frac{0.542}{\left[(1-K)\left(\varepsilon_{\mathrm{r}}+2\right)\right]^{1 / 3}},
$$

where $a_{\mathrm{H}}=e^{2} / 8 \pi \varepsilon_{\mathrm{r}} \varepsilon_{0} I_{\mathrm{d}}$ is the Bohr radius [m] for a single donor with the ionization energy $I_{\mathrm{d}}[\mathrm{J}]$; $e$ is the elementary charge $[\mathrm{C}] ; \varepsilon_{\mathrm{r}}$ is the relative permittivity; $\varepsilon_{0}$ is the electric constant $[\mathrm{F} / \mathrm{m}]$; $K=N_{\mathrm{a}} / N_{\mathrm{d}}$ is the compensation ratio.

Figure 1 shows the case of hopping electrical conduction via donors of two types with equal donor concentrations $N_{\mathrm{d} 1}=N_{\mathrm{d} 2} \approx 0.1 N_{\mathrm{M}}$ and the ratio of their compensation by acceptors $K=N_{\mathrm{a}} / N_{\mathrm{d} 1}=$ $=N_{\mathrm{a}} / N_{\mathrm{d} 2}=0.5$. In this case, the effective concentration of electrons hopping via both $\mid \mathrm{d} 1$ ) donors and $\mid \mathrm{d} 2$ ) donors is maximum [45].

When a reverse bias is applied (Figure $1 b$; $U_{\mathrm{r}}<0$ ), in the region where the type of doping donors changes, due to electron hopping the heat $Q_{\mathrm{ab}} \approx E_{\mathrm{d} 1}-E_{\mathrm{d} 2}$ will be absorbed, which is necessary to overcome the difference in the ionization energy of $\mid \mathrm{d} 1)$ and $\mid \mathrm{d} 2)$ donors. The junction region will cool down in this case. And vice versa, when a forward bias is applied (Figure $1 c ; U_{\mathrm{f}}>0$ ), in the region where the type of doping donors changes, due to electron transitions to deeper donors an excess of electron energy will be released in the form of heat $Q_{\mathrm{em}} \approx E_{\mathrm{d} 1}-E_{\mathrm{d} 2}$, and the junction region will heat up.

The typical temperature $T_{\mathrm{h}}$, at which the electrical conduction of a semiconductor is determined only by the hopping migration of electrons via hydrogen-like donors, is $T_{\mathrm{h}}=T_{\mathrm{j}} / 2$, where $T_{\mathrm{j}}$ is the temperature at which the $c$-band and hopping electrical conductivities are equal. The temperature $T_{\mathrm{j}}$ is given by the expression [46]:

$$
T_{\mathrm{j}}=\frac{0.728}{k_{\mathrm{B}}} \frac{e^{2}}{4 \pi \varepsilon_{\mathrm{r}} \varepsilon_{0}}\left(K N_{\mathrm{d}}\right)^{1 / 3},
$$

where $k_{\mathrm{B}}$ is the Boltzmann constant $[\mathrm{J} / \mathrm{K}]$; $e$ is the elementary charge $[\mathrm{C}] ; \varepsilon_{\mathrm{r}} \varepsilon_{0}$ is the dielectric constant of the crystal matrix $[\mathrm{F} / \mathrm{m}] ; N_{\mathrm{d}}=N_{\mathrm{d} 1}=N_{\mathrm{d} 2}$ is the concentration of the doping impurity $(\mid \mathrm{d} 1)$ and $\mid \mathrm{d} 2)$ donors) $\left[\mathrm{m}^{-3}\right]$. [Electrical neutrality condition: the concentration of donors in the charge state $(+1)$ is equal to the concentration of the negatively charged $(-1)$ compensating impurity (acceptors) $K N_{\mathrm{d}}$.]

In a doped semiconductor with compensation ratio $K \approx 0.5$, the ionization energy of hydrogen-like donors decreases with their concentration [47]:

$$
E_{\mathrm{d}}=I_{\mathrm{d}}\left(1-\frac{a_{\mathrm{H}}}{R_{\mathrm{res}}}\right),
$$

where $R_{\text {res }}=\left(2 \pi N_{\mathrm{d}}\right)^{-1 / 3}$ is the radius of the spherecal region of the crystal matrix per impurity atom (both donor and acceptor) at $K=0.5$. 

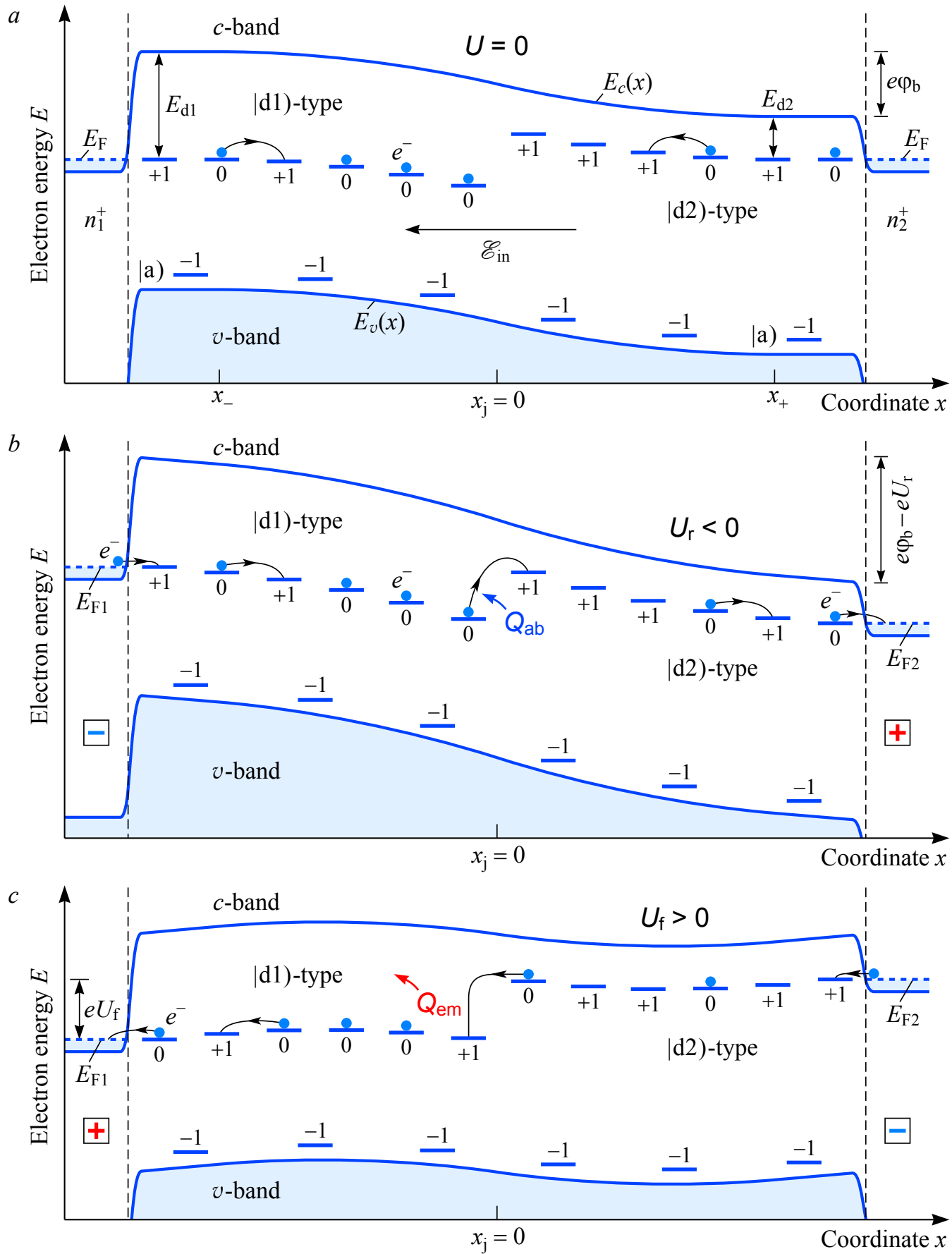

Figure 1 - Band diagrams (dependences of the single-electron energy $E$ on the coordinate $x$ ) at low temperatures for a Peltier element based on the $h$-diode, which is an $n$-type semiconductor doped with hydrogen-like donors of two types $\mid \mathrm{d} 1)$ and $\mid \mathrm{d} 2)$ with different thermal ionization energies $\left(E_{\mathrm{d} 1}>E_{\mathrm{d} 2}\right)$ and compensated by acceptors $\left.\mid \mathrm{a}\right)$ : in the equilibrium $(a ; U=0)$, under the reverse bias $\left(b ; U_{\mathrm{r}}<0\right)$ and under the forward bias $\left(c ; U_{\mathrm{f}}>0\right)$. The potential barrier height: $e \varphi_{\mathrm{b}}(a), e \varphi_{\mathrm{b}}-e U_{\mathrm{r}}(b), e \varphi_{\mathrm{b}}-e U_{\mathrm{f}}(c)$; the electrical double layer width is $\left(x_{+}-x_{-}\right)$. In the case of the reverse bias $(b$; $\left.U_{\mathrm{r}}<0\right)$, heat $Q_{\mathrm{ab}}$ is absorbed in the junction region and the structure cools down. Under the forward bias $\left(c ; U_{\mathrm{f}}>0\right)$, heat $Q_{\mathrm{em}}$ is released in the junction region and the structure heats up. The Peltier element operates in the vicinity of the temperature of realization of the hopping conductance $T_{\mathrm{h}}=T_{\mathrm{j}} / 2$, where $T_{\mathrm{j}}$ is given by Eq (5)

Note that to implement the device structure ( $h$ diode) with the Peltier effect on a $p$-type silicon crystal, in the capacity of $\mid \mathrm{a} 1)$ and $\mid \mathrm{a} 2)$ acceptors, we can take boron atoms (B) with the thermal ionization energy $I_{\mathrm{a} 1}=44.4 \mathrm{meV}$ and aluminium atoms (Al) with the ionization energy $I_{\mathrm{a} 2}=69 \mathrm{meV}$, respectively [43]. Antimony ( $\mathrm{Sb}$ ) or arsenic (As) atoms can be taken as compensating donors. 
A thermal cooler of this type can be used as a "cold finger" for bolometers [48] and infrared detectors [49] operating at cryogenic temperatures.

\section{Design 2 - hopping electron transfer in a partially disordered semiconductor}

A number of works (see, e. g., $[50,51]$ and references therein) describe the mechanisms of Fermi level "pinning" by point structure defects both at the metal-semiconductor interface and inside the semiconductor.

Let us consider the processes of transfer of electrons and energy in a "metal-partially disordered semiconductor-metal" device structure upon excitation of a stationary electric current in it.

The proposed scheme of a Peltier element based on a semiconductor with two energy levels $\left(E_{\mathrm{t} 1}\right.$ and $\left.E_{\mathrm{t} 2}\right)$ of point triple-charged $t$-defects [52, 53 ] is shown in Figure 2. We consider the case of hopping migration (drift and diffusion) of electrons via the upper level $E_{\mathrm{t} 2}$ only.

Note that triple-charged point defects can be introduced into a semiconductor by polyenergetic ion implantation (ion kinetic energy $>1 \mathrm{MeV} /$ nucleon) through contacts (electrodes) or by irradiation with fast reactor neutrons $[38,39]$.

Let us consider a one-dimensional model of the proposed device structure (Peltier element). A flat semiconductor sample is located between two metal electrodes (contacts); see Figure $2 a$. Two-level $t$ defects are created in the sample, each of which can be in one of three charge states $(-1,0,+1)$.

Let $t$-defects be immobile and uniformly distributed over the volume of the semiconductor:

$N_{\mathrm{t}}(x)=N_{\mathrm{t}}=$ const,

where $N_{\mathrm{t}}(x)=N_{\mathrm{t},-1}(x)+N_{\mathrm{t}, 0}(x)+N_{\mathrm{t}, 1}(x)$ is the total concentration of $t$-defects in all three charge states.

As can be seen from Figure $2 a, t$-defects contained in a semiconductor effectively reduce its band gap to a value of $\Delta_{\mathrm{t}}<E_{\mathrm{g}}$. The width of the energy gap between the average values of the energy levels of $t$-defects is $\Delta_{\mathrm{t}}=E_{\mathrm{g}}-\left(E_{\mathrm{t} 1}+E_{\mathrm{t} 2}\right)>3 k_{\mathrm{B}} T$. (Note that in a narrow-gap crystalline semiconductor, the band gap $E_{\mathrm{g}}$ is less than the electron affinity energy $\mathrm{EA}=E_{\mathrm{vac}}-E_{c}$, where $E_{\mathrm{vac}}$ is the vacuum level, $E_{c}$ is the bottom of the $c$-band).

The average value of the lower energy level $E_{\mathrm{t} 1}$ corresponds to the energy required for the transition of an electron from the $v$-band to the $t$-defect in the charge state $(+1)$. The average value of the upper energy level $E_{\mathrm{t} 2}$ corresponds to the energy required
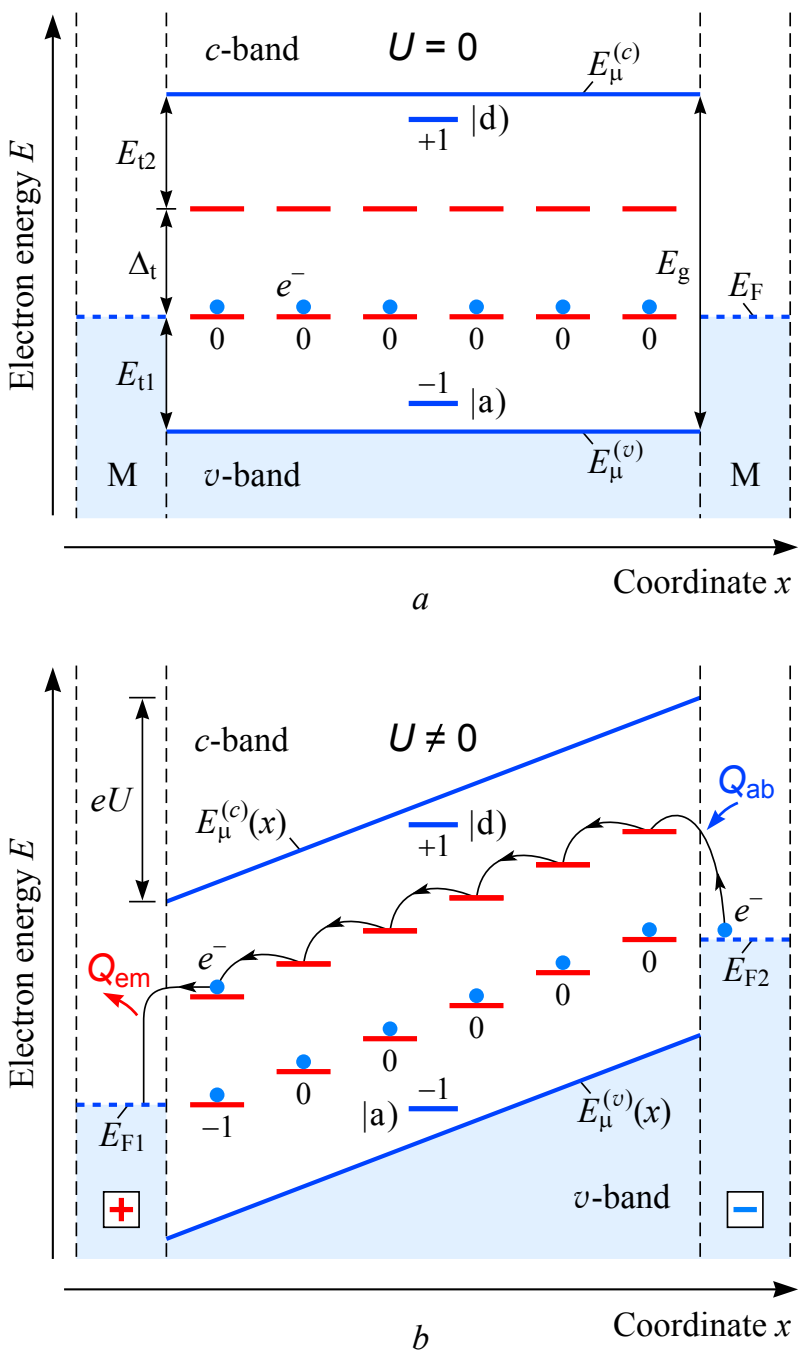

Figure 2 - Band diagrams $E(x)$ of the Peltier element in the thermodynamic equilibrium $(a ; U=0)$ and under the electrical bias $(b ; U \neq 0)$. A semiconductor (working substance) contains ions of donor $\mid$ d) and acceptors $\mid$ a) along with triple-charged $t$-defects. When a stationary hopping current is excited (for $U \neq 0$ ), the heat $Q_{\mathrm{ab}}$ is absorbed in the region of the contact under a negative potential and the contact cools down, and in the region of the contact under a positive potential, the heat $Q_{\mathrm{em}}$ is released and the contact heats up

for the transition of an electron from the $t$-defect in the charge state $(-1)$ to the bottom of the $c$-band. In a partially disordered semiconductors with a high concentration of defects, the energy positions of the edges of the allowed energy bands (the bottom of the $c$-band and the top of the $v$-band) fluctuate along the coordinate (have random deviations from the average value at different points of the crystal). When describing the electrical properties of such disordered semiconductors, the concept of the mobility edge (percolation threshold) for electrons 
in the $c$-band $E_{\mu}^{(c)}$ and holes in the $v$-band $E_{\mu}^{(v)}$ is introduced [54].

When an electrical bias is applied (Figure $2 b$; $U \neq 0$ ), in the region of contact under a negative potential a thermally stimulated transition of electron from a metal to a semiconductor occurs and the heat $Q_{\mathrm{ab}} \approx \Delta_{\mathrm{t}}$ is absorbed, which is necessary to overcome the energy difference between the upper level of $t$-defect $E_{\mathrm{t} 2}$ and the Fermi level $E_{\mathrm{F} 2}$ in metal. The contact region will cool down in this case. And vice versa, in the region of the opposite contact under a positive potential due to transitions of electrons from the $t$-defect upper level to the Fermi level $E_{\mathrm{F} 1}$ in metal, the excess of the electron energy is released in the form of the heat $Q_{\mathrm{em}} \approx \Delta_{\mathrm{t}}$, and the contact region will heat up.

In combination with radioisotope heater, the proposed Peltier element (Figure 2) becomes a generator of electrical energy. It is less susceptible to radiation degradation than an element based on conventional moderately doped semiconductor crystals, since it contains triple charged $t$-defects in a sufficiently high concentration, which were previously introduced into the crystal matrix.

A decrease in the thermal conductivity of a Peltier element occurs due to the creation in a semiconductor material (working substance) of a sufficiently large (for realization of electron hopping) number of point defects of structure, which effectively scatter phonons (both optical and acoustic) of all wavelengths [55]. For example, at cryogenic temperatures, the thermal conductivity of amorphous $\mathrm{SiO}_{2}$ is much lower than the thermal conductivity of crystalline $\mathrm{SiO}_{2}$ [56].

\section{Conclusion}

As Peltier elements with the electron hopping migration between electrical contacts to the semiconductor we proposed: (i) an $h$-diode containing inhomogeneously distributed along the semiconductor hydrogen-like donors of two types $\mid \mathrm{d} 1)$ and $\mid \mathrm{d} 2)$ in the charge states $(0)$ and $(+1)$, as well as uniformly distributed compensating ions of hydrogen-like acceptors; (ii) a semiconductor with uniformly distributed point $t$-defects in the charge states $(-1,0,+1)$ and ions of hydrogen-like donors and acceptors.

It is shown that in the $h$-diode under the reverse bias $\left(U_{\mathrm{r}}<0\right)$ for a cryogenic temperature, the region of the electric double layer between $\mid \mathrm{d} 1)$ - and $\mid \mathrm{d} 2$ )regions cools down, and under the forward bias $\left(U_{\mathrm{f}}>0\right)$ it heats up.
It is shown that in a Peltier element based on a semiconductor with triple-charged $t$-defects, upon current excitation, it is possible to cool down a metal-semiconductor contact under a negative electric potential and to heat up an opposite contact with a positive potential.

\section{Acknowledgments}

The work was supported by the Belarusian National Research Program "Materials Science, New Materials and Technologies".

\section{References}

1. Dresselhaus M.S., Chen G., Tang M.Y., Yang R., Lee H., Wang D., Ren Z., Fleurial J.-P., Gogna P. New directions for low-dimensional thermoelectric materials. Adv. Mater., 2007, vol. 19, no. 8, pp. 1043-1053.

DOI: 10.1002 /adma.200600527

2. Shevelkov A.V. Chemical aspects of the design of thermoelectric materials. Russ. Chem. Rev., 2008, vol. 77 , no. 1, pp. 1-19.

DOI: $10.1070 / \mathrm{RC} 2008 \mathrm{v} 077 \mathrm{n} 01 \mathrm{ABEH} 003746$

3. Snarskii A.A., Zhenirovskii M.I., Bezsudnov I.V. Limiting values of the quality factor of thermoelectric composites. Semiconductors, 2008, vol. 42, no. 1, pp. 80-85. DOI: $10.1134 /$ S1063782608010119

4. Dmitriev A.V., Zvyagin I.P. Current trends in the physics of thermoelectric materials. Phys. Usp., 2010, vol. 53 , no. 8, pp. 789-803.

DOI: $10.3367 /$ UFNe.0180.201008b.0821

5. Mani P., Nakpathomkun N., Hoffmann E.A., Linke H. A nanoscale standard for the Seebeck coefficient. Nano Lett., 2011, vol. 11, no. 11, pp. 4679-4681.

DOI: $10.1021 / \mathrm{nl} 202258 \mathrm{f}$

6. Upadhyaya M., Boyle C.J., Venkataraman D., Aksamija Z. Effects of disorder on thermoelectric properties of semiconducting polymers. Sci. Rep., 2019, vol. 9, no. 1, pp. 5820(1-11).

DOI: $10.1038 / \mathrm{s} 41598-019-42265-\mathrm{Z}$

7. Liu X., Wang Z. Printable thermoelectric materials and applications. Front. Mater., 2019, vol. 6, pp. $88(1-5)$. DOI: $10.3389 /$ fmats.2019.00088

8. Andreev A.G., Zabrodskii A.G., Egorov S.V., Zvyagin I.P. Thermopower of transmutation-doped Ge:Ga in the region for hopping conductivity. Semiconductors, 1997, vol. 31, no. 10, pp. 1008-1013.

DOI: $10.1134 / 1.1187015$

9. Andreev A.G., Zabrodskii A.G., Egorov S.V., Zvyagin I.P. Thermopower of neutron transmutation-doped Ge:Ga in the hopping region. Phys. Status Solidi B, 1998, vol. 205, no. 1, pp. 381-384.

DOI: 10.1002/(SICI)1521-3951(199801)205:1<381::AIDPSSB381>3.0.CO;2-W

10. Poklonski N.A., Lopatin S.Yu. A lattice model of thermopower in hopping conduction: application to 
neutron-doped crystalline germanium. Phys. Solid State, 2001, vol. 43, no. 12 , pp. 2219-2228.

DOI: $10.1134 / 1.1427945$

11. Ioffe A.F. Semiconductor Thermoelements and Thermoelectric Cooling. London, Infosearch, 1957, viii+184 p.

12. Nolas G.S., Sharp J., Goldsmid H.J. Thermoelectrics: Basic Principles and New Materials Developments. Berlin, Springer, 2001, viii +292 p.

DOI: $10.1007 / 978-3-662-04569-5$

13. Handbook of Thermoelectrics: Macro to Nano, ed. by D.M. Rowe. Boca Raton, CRC Press, 2006, 1014 p. DOI: $10.1201 / 9781420038903$

14. Sun P., Wei B., Zhang J., Tomczak J.M., Strydom A.M., Søndergaard M., Iversen B.B., Steglich F. Large Seebeck effect by charge-mobility engineering. Nat. Commun., 2015, vol. 6, pp. 7475(1-9).

DOI: $10.1038 /$ ncomms 8475

15. Gurevich Yu.G., Logvinov G.N. Physics of thermoelectric cooling. Semicond. Sci. Technol., 2005, vol. 20, no. 12, pp. R57-R64.

DOI: $10.1088 / 0268-1242 / 20 / 12 / \mathrm{R} 01$

16. Lu N., Li L., Liu M. A review of carrier thermoelectric-transport theory in organic semiconductors. Phys. Chem. Chem. Phys., 2016, vol. 18, no. 29, pp. 19503-19525. DOI: 10.1039/C6CP02830F

17. Masood K.B., Kumar P., Singh R.A., Singh J. Odyssey of thermoelectric materials: foundation of the complex structure. J. Phys. Commun., 2018, vol. 2, no. 6, pp. 062001(1-34). DOI: 10.1088/2399-6528/aab64f

18. Tomczak J.M. Thermoelectricity in correlated narrow-gap semiconductors. J. Phys.: Condens. Matter, 2018, vol. 30, no. 18 , pp. 183001(1-70).

DOI: $10.1088 / 1361-648 \mathrm{X} / \mathrm{aab} 284$

19. Recatala-Gomez J., Suwardi A., Nandhakumar I., Abutaha A., Hippalgaonkar K. Toward accelerated thermoelectric materials and process discovery. ACS Appl. Energy Mater., 2020, vol. 3, no. 3, pp. 2240-2257.

DOI: $10.1021 /$ acsaem.9b02222

20. DiSalvo F.J. Thermoelectric cooling and power generation. Science, 1999, vol. 285, no. 5428, pp. 703706. DOI: $10.1126 /$ science. 285.5428 .703

21. Vining C.B. Semiconductors are cool. Nature, 2001, vol. 413, no. 6856, pp. 577-578.

DOI: $10.1038 / 35098159$

22. Stafeev V.I. Thermoelectric and other phenomena in structures with nonequilibrium charge carriers and nanoparticles. Semiconductors, 2009, vol. 43, no. 10, pp. 1280-1287. DOI: $10.1134 / \mathrm{S} 1063782609100054$

23. Blakemore J.S. Electron capture and emission for midgap centers. J. Phys. Chem. Solids, 1988, vol. 49, no. 6, pp. 627-631.

DOI: $10.1016 / 0022-3697(88) 90193-\mathrm{X}$

24. Wilson A.H. Solid state physics 1925-33: opportunities missed and opportunities seized. Proc. R. Soc. Lond. A, 1980, vol. 371, no. 1744, pp. 39-48.

DOI: $10.1098 /$ rspa. 1980.0054

25. Shockley W. Electrons and Holes in Semiconductors with Applications to Transistor Electronics.
Princeton, D. Van Nostrand Co., Inc., 1950, xxiv+558 p.

26. Ross I.M. The invention of the transistor. Proc. IEEE., 1998, vol. 86, no. 1, pp. 7-28.

DOI: $10.1109 / 5.658752$

27. Kilby J.S. Turning potential into reality: The invention of the integrated circuit, in Nobel Lectures, Physics 1996-2000, ed. G. Ekspong. Singapore, World Scientific, 2002, pp. 474-485. DOI: 10.1142/4973

28. Smith G.E. Nobel Lecture: The invention and early history of the CCD. Rev. Mod. Phys., 2010, vol. 82, no. 3, pp. 2307-2312.

DOI: $10.1103 /$ RevModPhys.82.2307

29. Boyle W.S. Nobel Lecture: CCD-An extension of man's view. Rev. Mod. Phys., 2010, vol. 82, no. 3, pp. 2305-2306. DOI: 10.1103/RevModPhys.82.2305

30. Alferov Z.I. Nobel Lecture: The double heterostructure concept and its applications in physics, electronics, and technology. Rev. Mod. Phys., 2001, vol. 73, no. 3, pp. 767-782. DOI: $10.1103 /$ RevModPhys.73.767

31. Kroemer H. Nobel Lecture: Quasielectric fields and band offsets: teaching electrons new tricks. Rev. Mod. Phys., 2001, vol. 73, no. 3, pp. 783-793.

DOI: $10.1103 /$ RevModPhys. 73.783

32. Seebauer E.G., Kratzer M.C. Charged point defects in semiconductors. Mater. Sci. Eng. R, 2006, vol. 55, no. 3-6, pp. 57-149.

DOI: $10.1016 /$ j.mser.2006.01.002

33. Zhang Y. Electronic structures of impurities and point defects in semiconductors. Chin. Phys. B, 2018, vol. 27, no. 11, pp. 117103(1-14).

DOI: $10.1088 / 1674-1056 / 27 / 11 / 117103$

34. Oyama K., Ri S.-G., Kato H., Takeuchi D., Makino T., Ogura M., Tokuda N., Okushi H., Yamasaki S. Carrier transport of diamond $p^{+}-i-n^{+}$junction diode fabricated using low-resistance hopping $p^{+}$and $n^{+}$layers. Phys. Status Solidi A, 2011, vol. 208, no. 4, pp. 937-942. DOI: $10.1002 /$ pssa. 201026490

35. Poklonski N.A., Vyrko S.A., Poklonskaya O.N., Kovalev A.I., Zabrodskii A.G. Ionization equilibrium at the transition from valence-band to acceptor-band migration of holes in boron-doped diamond. J. Appl. Phys., 2016, vol. 119, no. 24, pp. 245701(1-10).

DOI: $10.1063 / 1.4954281$

36. Bulyarskii S.V., Svetukhin V.V., L'vov P.E. Thermodynamics of complex formation and defect clustering in semiconductors. Semiconductors, 2000, vol. 34, no. 4, pp. 371-375. DOI: $10.1134 / 1.1187990$

37. Coates R., Mitchell E.W.J. The optical and electrical effects of high concentrations of defects in irradiated crystalline gallium arsenide. Adv. Phys., 1975, vol. 24, no. 5, pp. 593-644.

DOI: $10.1080 / 00018737500101471$

38. Radiation Effects in Semiconductors, ed. by K. Iniewski. Boca Raton, CRC Press, 2011. xvi+415 p. DOI: $10.1201 / 9781315217864$

39. Brudnyi V.N. Charge neutrality in semiconductors: defects, interfaces, surface. Russ. Phys. J., 2013, vol. 56 , no. 7, pp. 754-756.

DOI: $10.1007 / \mathrm{s} 11182-013-0095-4$ 
40. Aronov D.A., Knigin P.I., Korolev Yu.S., Rubinov V.V. Exclusion effect in semiconductors with noninjecting contacts. Phys. Status Solidi A, 1984, vol. 81, no. 1, pp. 11-45. DOI: 10.1002/pssa.2210810102

41. Blank T.V., Gol'dberg Y.A. Mechanisms of current flow in metal-semiconductor ohmic contacts. Semiconductors, 2007, vol. 41, no. 11, pp. 1263-1292.

DOI: $10.1134 / \mathrm{S} 1063782607110012$

42. Poklonski N.A., Kovalev A.I., Gorbachuk N.I., Shpakovski S.V. [Calculation of static parameters of silicon diode containing $\delta$-layer of point triple-charged defects in symmetric $p-n$-junction]. Devices and Methods of Measurements, 2018, vol. 9, no. 2, pp. 130-141 (in Russian). DOI: 10.21122/2220-9506-2018-9-2-130-141

43. Madelung O. Semiconductors: Data Handbook. Berlin, Springer, 2004, xiv +692 p.

DOI: $10.1007 / 978-3-642-18865-7$

44. Poklonski N.A., Vyrko S.A., Zabrodskii A.G. Electrostatic models of insulator-metal and metalinsulator concentration phase transitions in $\mathrm{Ge}$ and $\mathrm{Si}$ crystals doped by hydrogen-like impurities. Phys. Solid State, 2004, vol. 46, no. 6, pp. 1101-1106.

DOI: $10.1134 / 1.1767252$

45. Poklonski N.A., Stelmakh V.F. Screening of electrostatic fields in crystalline semiconductors by electrons hopping over defects. Phys. Status Solidi B, 1983, vol. 117 , no. 1 , pp. 93-99.

DOI: $10.1002 /$ pssb.2220880266

46. Poklonski N.A., Vyrko S.A., Poklonskaya O.N., Zabrodskii A.G. Transition temperature from band to hopping direct current conduction in crystalline semiconductors with hydrogen-like impurities: Heat versus Coulomb attraction. J. Appl. Phys., 2011, vol. 110, no. 12 , pp. 123702(1-7). DOI: $10.1063 / 1.3667287$

47. Poklonski N.A., Vyrko S.A., Dzeraviaha A.N. Thermal ionization energy of hydrogen-like impurities in semiconductor materials. Journal of the Belarusian State
University. Physics, 2020, no. 2, pp. 28-41 (in Russian). DOI: $10.33581 / 2520-2243-2020-2-28-41$

48. Kuz'min L.S. Supersensitive cold-electron bolometers in studies of dark matter and dark energy. Phys. Usp., 2005, vol. 48, no. 5, pp. 519-525.

DOI: $10.1070 /$ PU2005v048n05ABEH002128

49. Rogalski A. Progress in focal plane array technologies. Prog. Quant. Electron., 2012, vol. 36, no. 2-3, pp. 342-473. DOI: 10.1016/j.pquantelec.2012.07.001

50. Kiselev V.A. Covalent-ionic transition, and activity of metal-semiconductor interfaces. Sov. Phys. Solid State, 1991, vol. 33, no. 10, pp. 3070-3076.

51. McPherson M. Fermi level pinning in irradiated silicon considered as a relaxation-like semiconductor. Physica B, 2004, vol. 344, no. 1-4, pp. 52-57.

DOI: $10.1016 /$ j.physb.2003.07.006

52. Poklonski N.A., Vyrko S.A., Zabrodskii A.G. Field effect and capacitance of silicon crystals with hopping conductivity over point radiation defects pinning the Fermi level. Semiconductors, 2007, vol. 41, no. 11, pp. 1300-1306.

\section{DOI: $10.1134 / \mathrm{S} 1063782607110048$}

53. Poklonski N.A. Disordered semiconductor materials. Int. Winter School on Semiconductor Physics 2019: Scientific Programme and Abstracts, St. Petersburg Zelenogorsk, Feb. 28-Mar. 4, 2019, SPb., Ioffe Institute, 2019, pp. 40-44 (in Russian).

54. Mott N. The mobility edge since 1967. J. Phys. C: Solid State Phys., 1987, vol. 20, no. 21, pp. 30753102. DOI: $10.1088 / 0022-3719 / 20 / 21 / 008$

55. Kozub V.I., Rudin A.M. Transport of nonequilibrium phonons in disordered systems (review). Phys. Solid State, 1996, vol. 38, no. 2, pp. 189-208.

56. Smolyakov B.P., Khaimovich E.P. Dynamic processes in dielectric glasses at low temperatures. Sov. Phys. Usp., 1982, vol. 25, no. 2, pp. 102-115.

DOI: $10.1070 /$ PU1982v025n02ABEH004500 